\title{
LOS TESTIMONIOS DE ARISTÓTELES SOBRE EL NOÛS DE ANAXÁGORAS
}

\author{
DAVID TORRIJOS-CASTRILLEJO \\ Universidad Eclesiástica San Dámaso, Madrid
}

\begin{abstract}
RESUMEN: Uno de los aspectos de la filosofía de Anaxágoras que más interesan a Aristóteles es su teoría del noûs. Sin embargo, al respecto mantiene una postura algo bivalente, pues, por una parte, alaba al presocrático por haber puesto el noûs como principio, mientras que, por otra, se muestra decepcionado. El noûs de Anaxágoras intervendría de modo insuficiente en el universo pero también causaría el bien, es más, sería el Bien con mayúscula. Nuestro objetivo es explicar cómo Aristóteles es capaz de desarrollar ambos tipos de discurso sobre el presocrático, siendo entre ellos aparentemente contradictorios. Se ofrecen dos soluciones a esta disyuntiva: aun existiendo cierta teleología en la filosofía de Anaxágoras, ésta resulta insuficiente a los ojos de Platón y Aristóteles; la recepción del pensamiento de Anaxágoras en otros autores posteriores, pero anteriores a Aristóteles, asocia subrepticiamente la bondad con el noûs.
\end{abstract}

PALABRAS CLAVE: Anaxágoras; Aristóteles; bien; causalidad; mecanicismo; noûs; Platón; teleología.

\section{The testimonies of Aristotle about the nous of Anaxagoras}

ABSTRACT: Anaxagoras' theory of the nous constitutes one aspect of his philosophy particularly interesting for Aristotle. However, he maintains a somewhat bivalent position about it: on the one hand, he praises the Presocratic philosopher for putting the nous as the first principle, while on the other, he shows his disappointment. According to him, Anaxagoras' nous works insufficiently in the universe, but it is also the cause of goodness, indeed it is the Good capitalized. Our goal is to explain how Aristotle was able to develop both types of seemingly inconsistent discourse concerning Anaxagorean nous. Two solutions to this dilemma are offered: even although some teleology exists in Anaxagoras' philosophy, it is insufficient for Plato and Aristotle; the reception of the thought of Anaxagoras in later authors still before Aristotle furtively associates goodness with nous.

KEY WORDS: Anaxagoras; Aristotle; goodness; causality; mechanism; nous; Plato; teleology.

El propósito de estas páginas es comprender cómo Aristóteles sea capaz de ofrecer dos interpretaciones del noûs de Anaxágoras aparentemente encontradas entre sí. Por una parte, el Estagirita alaba su ingenioso discurso frente a las necedades balbuceadas por los demás filósofos de la naturaleza. Por otra parte, es criticado debido a su insatisfactoria comprensión de la teleología. Sin embargo, en otras ocasiones da por sentado que el noûs de Anaxágoras no sólo produce bondad en el universo, sino que incluso debe ser considerado como el Bien (con mayúscula) dentro de su sistema ${ }^{1}$. Aunque estas últimas paradójicas afirmaciones no hayan sido suficientemente analizadas - a veces, ni siquiera advertidas-, ello no ha impedido que las otras, es decir, los testimonios críticos del Estagirita sobre este particular, sí hayan desatado ríos de tinta entre los comentaristas, cuestionando así la eventual dimensión

1 Esta cuestión motivó en parte mi trabajo Torrisos-Castrillejo, D., Anaxágoras y su recepción en Aristóteles, EDUSC, Romae, 2014, tal como indico en la introducción (pp. 20-21). 
teleológica de la filosofía de Anaxágoras. Creemos que un examen de los textos de Aristóteles puede explicar esta desconcertante situación y a la vez arrojar algo de luz sobre el pensamiento del filósofo de Clazomene. Por otra parte, los pensadores intermedios entre ambos no deben ser pasados por alto, pues su manera de abordar tales cuestiones podría contribuir a explicar el punto de vista adoptado por Aristóteles.

\section{1. El Sócrates del Fedón y el nOÛS de AnaXÁgoras}

En el primer libro de la Metafísica, Anaxágoras aparece colmado de elogios por parte de Aristóteles, mostrándose «sensato en comparación con los desatinados parloteos de los anteriores» porque afirmaba que un mismo principio era «causa de la belleza» $\mathrm{y}$ «el origen de donde surge el movimiento» ${ }^{2}$. Sin embargo, algo más adelante, tras haber prodigado tales alabanzas, parece recapacitar y niega a Anaxágoras el mérito de haber acertado a poner el noûs como causa del movimiento y del bien en los entes, excepto como fruto de un azaroso proceder en la tarea intelectual. Así, después de haber comparado la escasa ciencia del Clazomenio con la ineptitud de un púgil principiante que sólo asesta buenos golpes por casualidad, afirma:

Anaxágoras se vale artificiosamente del entendimiento para la confección del mundo y, así, cuando duda sobre la causa por la cual algo sucede necesariamente, entonces lo saca a escena, mientras que para el resto de los acontecimientos prefiere asignar cualquier causa antes que el entendimiento. ${ }^{3}$

De esta manera, la exposición de Aristóteles nos recuerda enseguida al examen de las doctrinas de Anaxágoras llevado a cabo por Sócrates en el Fedón. Igual que Aristóteles, Sócrates expresa su personal tránsito desde una ilusionada impresión inicial despertada por la ingeniosa introducción del noûs como causa última del devenir, hasta una final decepción al ver en qué paraba dicha teoría:

Habiendo escuchado leer entonces en cierto libro - escrito, según se decía, por Anaxágoras- que el entendimiento había ordenado todo y de todo era causa, semejante causalidad me alegró mucho y pensé la manera por la cual estaría bien que el entendimiento fuera la causa de todas las cosas.

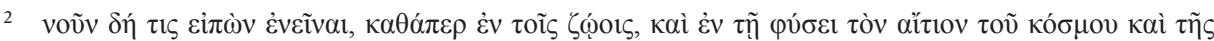

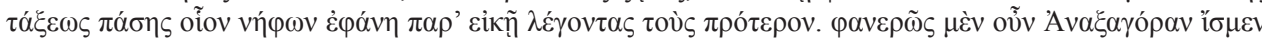

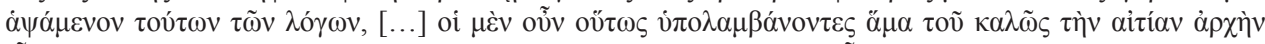

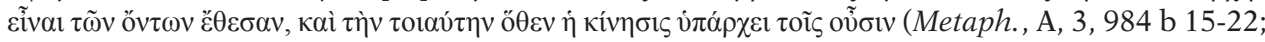
DK 59 A 58; LM 25 R 9). A menos que indique lo contrario, las traducciones son mías. DK = Diels, H., Kranz, W., Die Fragmente der Vorsokratiker, Weidmann, Berlin, 1951-75; LM = LaKs, A., Most, G. W., Les débuts de la philosophie. Des premiers penseurs grecs à Socrate, Fayard, Paris, 2016.

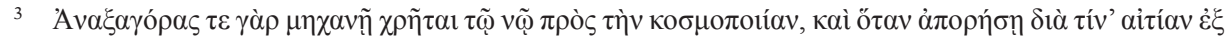

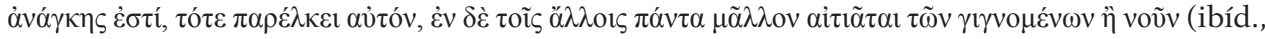
4, 985 a 18-21; DK 59 A 47; LM 25 R 10). 
Razoné que, si esto era así, el entendimiento ordenador ordenaría todas las cosas y, de igual modo, también dispondría cada una para que se encontrara de la mejor manera posible [...]. Sin embargo, amigo mío, hube de apartarme enseguida de esta maravillosa esperanza. En cuanto avancé un poco en la lectura, reconocí que aquel hombre no se valía para nada del entendimiento ni de otras causas que justificaran el orden del mundo y de los seres, sino que recurría a aires, éteres, aguas y otras muchas cosas improcedentes. ${ }^{4}$

No es extraño que, en su célebre colección de textos, Diels introdujese este pasaje junto al testimonio aristotélico citado poco antes, puesto que ambos parecen compartir el mismo punto de vista: Anaxágoras ha acertado en parte, pero todo el entusiasmo que puede suscitar su teoría, se ve desvanecido cuando uno se fija en cómo hace uso de ella. Ambos filósofos creen que el protagonismo otorgado al noûs es menor del adecuado y en su lugar se da excesiva prioridad a otras causas materiales. Frente a tales entes, la peculiaridad del noûs en cuanto causa - para Platón y Aristóteles - no consistiría en ser una mera causalidad final, como se podría expresar vagamente, sino más bien en la causalidad propia de un causante inteligente, es decir, un agente apto para perseguir eficazmente fines. La causalidad final sola, según Aristóteles, no puede producir un efecto sino «metafóricamente», pues es formalmente distinta de la causalidad eficiente $^{5}$. Al contrario, consiste justamente en la orientación concreta hacia la cual se dirige la causa eficiente. Por eso mismo, aquí se trata sobre todo de una causalidad eficiente ejercida por un agente inteligente, el cual es capaz de determinar por sí mismo la finalidad hacia la cual orienta su acción y de inclinarse así hacia cosas opuestas ${ }^{6}$.

Desde el punto de vista aristotélico, que — como vemos- hiende sus raíces en Platón, la teoría de Anaxágoras ofrecería grandes ventajas científicas para explicar el origen del mundo en comparación con los planteamientos seguidos por otros filósofos de la naturaleza. A diferencia de ellos, la causalidad inteligente del primer principio eficiente explicaría el orden presente en la naturaleza. Este orden únicamente podría verse garantizado por semejante causa, pues sólo ella sería capaz de disponer la materia de tal modo que se obtuvieran los mejores resultados. Abandonadas las causas irracionales a sí mismas, producirían los entes sin atenerse a patrón alguno, por lo que sus efectos no podrían originar la armonía que contemplamos en el mundo. Tal producto no sería algo verdaderamente "natural» sino más bien «monstruoso»,

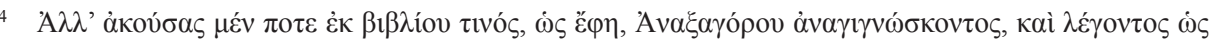

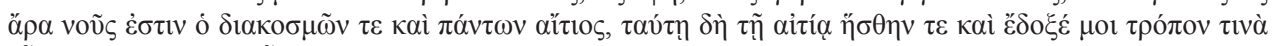

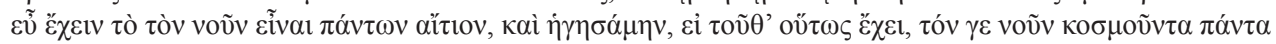

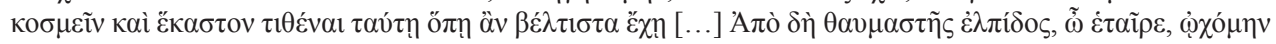

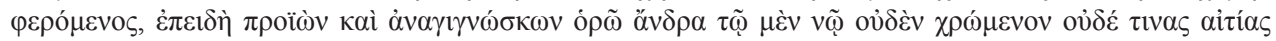

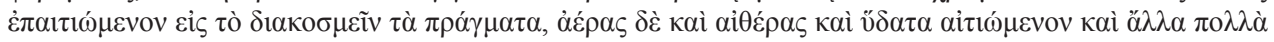

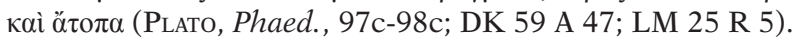

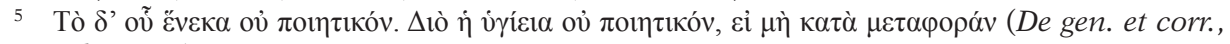
I, 7, 324 b 14-15).

6 Cf. Plato, Tim., 46e; Aristoteles, Metaph., $\Theta, 2,1046$ a 36ss. 
pues la naturaleza, tal como haría un sensato artesano, persigue siempre un fin ${ }^{7}$. Por ello, lo natural puede ser cabalmente «bueno» y tener su propio «bien» ${ }^{8}$. En este sentido, una inteligencia guía del cosmos también sería garante de una teleología cuyo último término fuera el «bien». Sin embargo, tanto Platón como Aristóteles convienen en que Anaxágoras habría empleado de hecho su noûs demasiado escasamente, de manera que muchas de las cosas «buenas» presentes en el mundo sólo podrían haberse originado por casualidad.

Si volvemos la mirada a los fragmentos de Anaxágoras conservados (DK 59 B 12-14; LM 25 D 27-29), descubriremos la imposibilidad de negar que el noûs sea una realidad activa, pues ciertamente es moviente y constituye la causa de la cosmogonía y de todo el devenir del universo. Es responsable de las revoluciones celestes, las cuales desencadenarían últimamente los cambios meteorológicos y los demás sucesos. Es probable que la explicación pormenorizada de cada uno de estos fenómenos (eclipses, rayos, terremotos, incendios espontáneos, etc.) estuviese en otra parte del tratado que hemos perdido y en ella no se hablase en absoluto del nô̂s. Sin embargo, sí sabemos que Anaxágoras «usa» del noûs tanto que lo hace soberano incluso de cada uno de los vivientes ${ }^{9}$. Ahora bien, un repaso de los fragmentos enseguida nos convencerá de que el «bien» o la «mejor constitución» de las cosas, de un modo análogo al planteado, por ejemplo, en el Timeo, es una cuestión por completo ajena a los intereses del filósofo de Clazomene. Es más, la relación del noûs con la bondad es un tema por entero omitido por los demás doxógrafos posteriores a Aristóteles.

Si tan sólo dispusiéramos de estos datos, podríamos pensar que el Sócrates de Platón insirió una cuestión no pertinente aquí, la cual únicamente podría servir de obstáculo para comprender el verdadero pensamiento de Anaxágoras. Este foráneo planteamiento habría sido retomado en la crítica de Aristóteles contra Anaxágoras y después se perdería en la historia. Sin embargo, esta respuesta no es del todo conclusiva porque no acaba de justificar las repetidas afirmaciones en las que Aristóteles - diríase que contradiciendo el parecer de Sócrates- pone al noûs provocando el bien en los entes, llegando a afirmar que él mismo es el bien.

\section{Aristóteles, el nốs de AnaXÁgoras y el bien}

En primer lugar, vamos a llamar la atención sobre los pasajes donde Aristóteles deliberadamente atribuye al noûs el origen del bien en el cosmos. El primero de ellos podría ser el citado paso donde se declara lo siguiente:

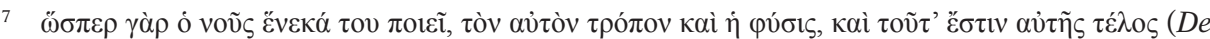
an., II, 4, 415 b 16-17; cf. Metaph., K, 8, 1065 a 26 - 1065 b 4).

8 Cf. Phys., VIII, 7, 260 b 22-23; De gen. an., I, 4, 717 a 15-16.

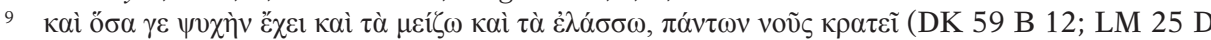
27). Se trata de un pasaje evocado por Aristóteles en De an., I, 2, 404 b 1-5. 
[...] para que los entes estén bien y sean hermosos o para que esta buena condición y belleza se genere en los entes, no parecen causas proporcionadas ni el fuego, ni la tierra, ni nada similar, ni tan siquiera aquéllos [sc. los primeros «filósofos de la naturaleza»] lo creyeron así. Tampoco podría abandonarse la belleza de un objeto a la arbitraria espontaneidad y a la suerte. Así, diciendo uno que, como en los vivientes, también en la naturaleza había un entendimiento y constituía la causa de todo orden y concierto, se demostró sensato. ${ }^{10}$

Como decíamos hace un momento, Aristóteles simpatiza con esta concepción de la primera causa como un ser inteligente en virtud de cuya ciencia es explicable el orden natural, pues ofrece una versatilidad en su actividad que le está vedada a las meras causas naturales. De tal modo, puede escoger el efecto que mejor conviene en cada caso a fin de alcanzar la perfección debida a cada ente.

En otra ocasión, aúna a Anaxágoras con Empédocles, con quien estaría de acuerdo en cierto planteamiento dualista por el cual habría un principio para el bien y otro para el mal ${ }^{11}$. En Empédocles es fácil identificar el bien con la amistad y el mal con la lucha, tratándose ambos de principios movientes. En Anaxágoras, en cambio, ha de suponerse que el principio procurador del bien es el noûs, mientras que la mezcla, el conjunto de los seres fusionados entre los cuales aquél introduce orden, sería el principio del mal. En todo caso, está claro que Aristóteles apela ahí al sistema de Anaxágoras como un precedente del de Platón, donde ambos principios también serían, respectivamente, la causalidad formal y la material: el Uno y la Díada.

En definitiva, a pesar de que muy probablemente Anaxágoras no hablara nunca de la bondad o de la belleza del mundo ni mucho menos se valiese de tales conceptos con valor explicativo, Aristóteles no se recata en afirmar que "Anaxágoras establece el Bien como principio en cuanto moviente, pues el entendimiento mueve» ${ }^{12}$. Es más, lejos de atribuirle circunspectamente dicho proceder en alguna ocasión aislada, llega a afirmar que «muchas veces ${ }^{13}$ dice que la causa de lo bello y lo recto es el entendimiento» ${ }^{14}$. Vemos como la

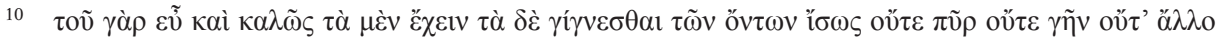

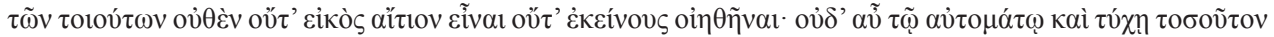

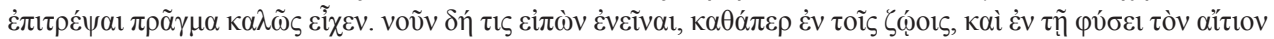

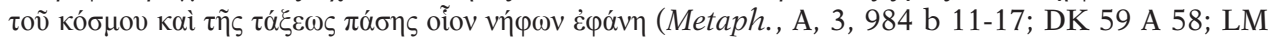
25 R 9).

11 Cf. Metaph., A, 6, 988 a 7-17; 7, 988 b 6-16.

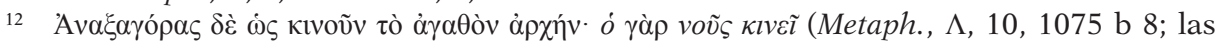
palabras griegas en cursiva evocan el fragmento DK 59 B 13; LM 25 D 29b).

13 Gigon, uno de los pocos autores que se detienen en la identificación entre ó voṽ $\varsigma$ y

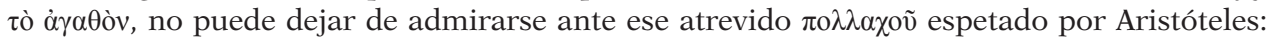
cf. Gigon, O., "Anaxagoras bei Platon und Aristoteles», en: Boudouris, K. J. (ed.), Ionian philosophy, International Association for Greek Philosophy and International Center for Greek Philosophy and Culture, Athens, 1989, p. 162.

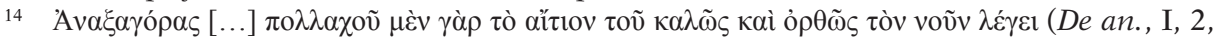
404 b 1-2; DK 59 A 99). 
asimilación del pensamiento de Anaxágoras con el de Platón facilita, al parecer, no sólo asignar a la actuación del noûs el bien en el mundo, sino que asimismo lleva a ver en él el bien como tal. No obstante, permanecen abiertas algunas cuestiones: si esta tendencia sólo es debida a Platón y, en último término, qué hay en la doctrina de Anaxágoras que permita, a un pensador tan agudo como Aristóteles, caer en semejante inexactitud.

Antes de nada se debe plantear la siguiente cuestión: ¿contradecía Aristóteles a Sócrates cuando reprochaba a Anaxágoras no hacer del noûs una causa de lo mejor? A decir verdad, esta misma reinterpretación del sistema del presocrático a la luz del propio pensamiento aristotélico y de la crítica dirigida contra Platón es también responsable de aquellas recriminaciones. Aristóteles se muestra solidario con el Sócrates platónico en su comprensión de Anaxágoras. En efecto, a pesar de ser productor de bienes, el noûs no es suficientemente inteligente porque no es capaz de ordenar las cosas hacia el bien verdadero y digno de ser tomado como fin. Veámoslo en un pasaje omitido por Diels pero acertadamente recogido en la excelente — pero demasiado olvidada- colección de Lanza:

Aquello por mor de lo cual se llevan a cabo las acciones, cambios y movimientos lo llaman en cierto modo causa, pero no lo dicen expresamente ni que lo sea por naturaleza. Los que hablan del entendimiento o de la amistad como si fueran el Bien, introdujeron tales causas, pero no tratan esas cosas como aquello por mor de lo cual existe o se genera algo de los entes, sino como aquello de donde proceden los movimientos. Igualmente, quienes afirman que lo Uno y lo Ente constituyen tal naturaleza, sostienen que son la causa de la sustancia, pero no es ni se genera por mor de ellos, de manera que a éstos les sucede que, en cierto modo, dicen y no dicen que el bien es causa, porque no se expresan en sentido absoluto sino por accidente. ${ }^{15}$

El objetivo de estas palabras de Aristóteles no es, como aseguró Lanza, «subrayar la incompatibilidad de la causa eficiente y la final» ${ }^{16}$. En efecto, antes dijimos que ambas se excluyen formalmente entre sí, pero ello no significa que el mismo sujeto no pueda ejercer las dos bajo distintos aspectos. Por el contrario, el núcleo de la crítica reside en que el noûs ve mermada su condición de bien no por ser causa eficiente, sino porque su eficiencia se ve dirigida

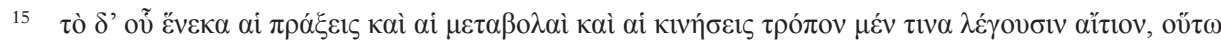

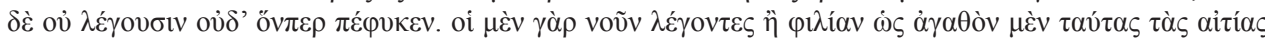

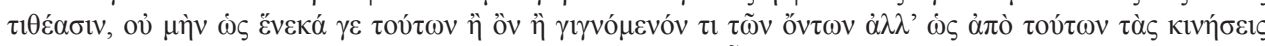

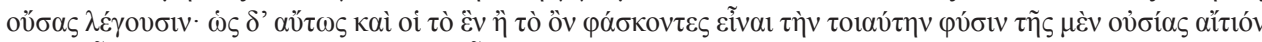

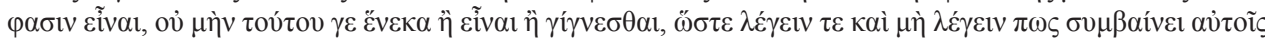

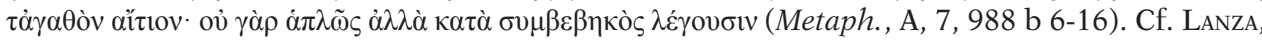
D., Anassagora. Testimonianze e frammenti, La Nuova Italia, Firenze, 1966, p. 112, A 58. Se debe encomiar la reciente edición de Laks-Most por retomar el trabajo de Lanza, si bien tampoco ella recoge este pasaje.

16 «Aristotele vuol qui sottolineare l'incompatibilità della causa efficiente e di quella finale» (LANZA, ibíd., p. 113). 
hacia fuera de sí mismo, mostrándose dependiente respecto de otra entidad anterior a él: «[...] no tratan esas cosas como aquello por mor de lo cual existe o se genera algo de los entes». La cuestión es que el noûs parece encontrarse «extrovertido», perdiéndose en la realización de la bondad cósmica, pero no se tiene a sí mismo como el bien digno de ser realizado ${ }^{17}$. Es la misma objeción que Aristóteles pone a Anaxágoras en otro lugar: «Anaxágoras establece el bien como principio en cuanto moviente, pues el entendimiento mueve; pero mueve por mor de algo, luego se trata de algo distinto, a menos que suceda como decimos nosotros: la medicina es en cierto modo la salud» ${ }^{18}$. Corrige así la propuesta de Anaxágoras, pues cabría la posibilidad de que el noûs estuviese orientado hacia sí mismo como motivo de su actuación, teniéndose a sí mismo por fin ${ }^{19}$. Esto no le impediría provocar cambios en el mundo puesto que el objetivo perseguido en semejante acción eficiente estaría precedentemente en él, del mismo modo como el médico posee la salud en su mente antes de suscitarla en el paciente. De tal modo queda suprimido todo temor a una «extroversión» del noûs porque, si bien obra eficazmente en el mundo, se trataría de uno de esos casos enunciados por Aristóteles en que el causante no sufriría afección

17 Mejor lo vieron Bonitz y Brentano. Bonitz, H., Aristotelis Metaphysica, vol. 2, Marcus, Bonnae, 1849, p. 522 (ad 1075 a 28 - 1075 b 16): «In Anaxagoras autem id quidem recte vituperat, b8, quod qua ratione intellectus moveat ostendere omiserit; debebat autem Anax., quod hic breviter Ar. significat [...], ad eam devenire rationem, ut intellectum sui ipsius intelligentiam ideoque sui ipsius $\tau \dot{\varepsilon} \lambda o \varsigma$ esse statueret». Brentano, F. C., Die Psychologie des Aristoteles, Franz Kirchheim, Mainz, 1867, p. 235: «Er tadelt ihn [sc. Anaxagoras] nicht desshalb, weil er den voũ s als bewegendes Princip gefasst, sondern weil er nicht gezeigt habe, wie der Zweck mit diesem bewegenden Principe selbst identisch sein könne». Sobre la importancia que Brentano daba a Anaxágoras incluso a la hora de entender el personal punto de vista de Aristóteles, véase Torrios Castrillejo, D., «Propuestas de Franz Brentano para una correcta interpretación de Aristóteles», Pensamiento 73 (2017), p. 39.

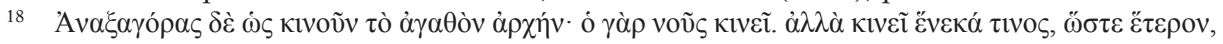

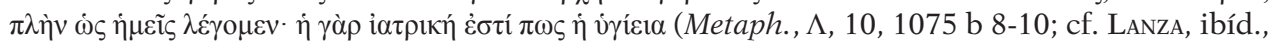
A 58).

19 Es importante para comprender los testimonios de Aristóteles no dar por sentado que todos van en una sola dirección, porque abordan los autores referidos con distintas perspectivas en función del contexto. En éstos, Aristóteles está considerando el noûs como Bien en cuanto productor de bien, sin embargo, su condición de Bien subsistente no estaría suficientemente definida al no ponerse a sí mismo como término de su obrar sino, al parecer, el bien producido (aquello que se toma por fin es mejor, luego el noûs no sería tan bueno como sus productos). En este sentido, la filosofía de Anaxágoras se aproximaría, no sin paradoja, a la de Espeusipo, con la cual Aristóteles la enfrenta justamente en este punto: según él, Anaxágoras habría adivinado con más lucidez que este discípulo de Platón la anterioridad del Bien, pues no cabría que fuera fruto del desarrollo cosmogónico. Espeusipo debía de pensar que el bien no es una realidad originaria sino exclusivamente el resultado del devenir (Metaph., $\Lambda, 7,1072$ b 31). Aristóteles, en cambio, que considera el Bien como algo preexistente en el moviente antes que en lo movido (ibíd., 10, 1075 a 1115), pone la filosofía de Anaxágoras como ejemplo de esta prioridad del Bien, en cuanto defendería la anterioridad del acto frente a la potencia: cf. ibíd., $\Lambda, 6,1072$ a 3-6; N, 4, 1091 a 29 - 1091 b 15. 
alguna al producir un cambio $^{20}$. No cabe duda de que dicha comprensión del noûs sería análoga al motor inmóvil del Estagirita sobre todo si consideramos que, para él, el noûs de Anaxágoras también es «inmóvil» ${ }^{21}$.

\section{El noûs de AnaXágoras y la teleología, según Aristóteles}

Por lo que hemos visto, Aristóteles está en desacuerdo con Anaxágoras en su comprensión de la actividad productiva del nô̂s debido a su incorrecta exposición de la teleología. Según él, el filósofo de Clazomene no habría establecido adecuadamente el fin por el cual obra el noûs. A decir verdad, no es la única ocasión en que el Estagirita pone objeciones a esta faceta del pensamiento de Anaxágoras. En un pasaje de su tratado Sobre las partes de los animales, escribe las siguiente líneas:

Anaxágoras dice que el hombre es el más prudente de todos los animales por tener manos; pero en realidad es más razonable suponer que tiene manos por ser el más prudente. Las manos son un instrumento y la naturaleza siempre distribuye todo como un hombre prudente, dándole a cada uno lo que es capaz de utilizar. ${ }^{22}$

Este texto quiere poner en evidencia un déficit de la explicación teleológica en el pensamiento de Anaxágoras. Éste buscaba el procedimiento para argumentar cómo se había llegado hasta el presente estado de cosas, pero no justificaba por qué esta situación merecía haber sido tomada por el noûs como objetivo. La eventual bondad de los hechos era ignorada y éstos eran asumidos como un factum que tan sólo debía ser explicado en función de sus causas eficientes. Sin embargo, estos «hechos», que Aristóteles —en virtud de su propio punto de vista- sobreentiende como bienes, se sitúan en un puesto de preeminencia respecto de todo aquello que conduce hasta ellos. Para Aristóteles el resultado no sólo es efecto de causas eficientes sino que éstas se dirigen hacia él por la bondad ínsita en él. Pero la bondad debe preexistir en la causa para que la causa sea más digna que el efecto.

Acordémonos ahora de lo que dijimos antes sobre el noûs, el cual, al estar subordinado a un motivo ulterior a sí mismo (los «bienes» alcanzados), perdía su naturaleza de causa última, convirtiéndose en algo condicionado por otra realidad anterior. Por esta razón, Aristóteles se quejaba en su

20 Cf. De gen. et corr. I, 6, 323 a 31-32.

21 Cf. Phys., VIII, 5, 256 b 24-27; DK 59 A 56; LM 25 R 11. Traté sobre la similitud entre los planteamientos de ambos filósofos griegos a este respecto en ToRRIJOs CASTRILLEJo, D., «La causalidad del motor inmóvil», Hypnos 31 (2013), pp. 243-245.

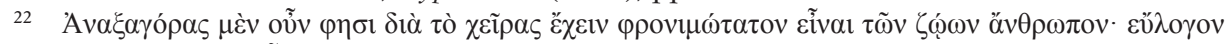

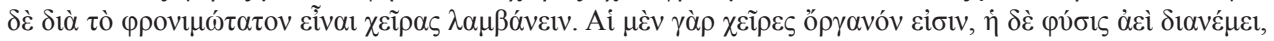

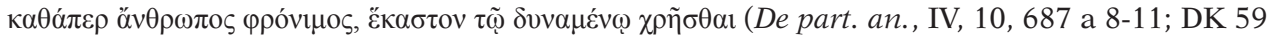
A 102; LM 25 D 80). 
momento del uso «instrumental» y —por así decir- «artificioso» $\left(\mu \eta \chi \alpha v \tilde{n ̃ n}^{23}\right)$ que Anaxágoras hacía de su principio. Este reproche me convence de que lo pernicioso de la fisiología del Clazomenio a los ojos de Aristóteles estaría en una inversión de los fines: las manos deberían servir al entendimiento pero, para el presocrático, el hombre se serviría del entendimiento con el objeto de mover las manos. Lo mismo sucedería en el universo todo, de suerte que el nô̂s, en lugar de ser soberano de todas las cosas, orientándolas según sus propósitos, se convertiría en un mero expediente para alcanzar ciertos objetivos superiores a él ${ }^{24}$.

A pesar de todo, no podemos dejar de afirmar que el noûs obraría en verdad de un modo inteligente, pues, como Aristóteles afirma de manera expresa, «el entendimiento obra pensando ${ }^{25}$. Ahora bien, eso significaría nada más -y nada menos- que sería capaz de organizar su operación con gran pericia técnica, obteniendo resultados a partir de la combinación de unas tareas y determinados materiales. El noûs se comportaría como un diestro artesano, hábil para efectuar esmerados trabajos ${ }^{26}$. Sin embargo, desde el punto de vista de Platón y Aristóteles, este artesano no tendría dote alguna para el gobierno de una gran empresa, como se esperaría, por ejemplo, de un arquitecto, un general o un piloto de navío ${ }^{27}$. Si hubiera manifestado verdadera sabiduría -en el ejemplo de las manos que aparece en el pasaje antes citado-, no se habría limitado a componer de cierto modo unos ingredientes previos hasta producir

23 Metaph., A, 4, 985 a 18; DK 59 A 47; LM 25 R 10. Ante tal expresión, enseguida se piensa en el deus ex machina, cuya irrupción en la tragedia es reprobada por Aristóteles en su Poética (15, 1454 a 37 - 1454 b 3). CANFora, L., Una società premoderna. Lavoro, morale, scrittura in Grecia, Dedalo, Bari, 1989, p. 224 se refiere al testimonio de Vitrubio acerca de los estudios de Anaxágoras sobre la tragedia: De architectura, VII, pr. 11; DK 59 A 39; LM 25 D 97. Ahí Vitrubio podría haber llegado a designar al pensador de Clazomene con la calificación de philosophus scaenicus (ibíd., VIII, pr.; no está claro si lo afirma de Eurípides o de Anaxágoras). Según Canfora, su testimonio proporciona una prueba ulterior para sostener que «vi è un interesse di Anassagora per il teatro che ribadisce il suo rapporto con Euripide ("auditor Anaxagorae")». No es casual, pues, que Aristóteles atribuya a Anaxágoras el vicio de la introducción del deus ex machina que también compartirá su «discípulo» Eurípides.

24 Cf. Torrijos-Castrillejo, D., Anaxágoras y su recepción en Aristóteles, pp. 259-260. Según creo, esta interpretación podría verse apoyada por la recurrente aparición del tema de la «utilización» $(\chi \rho \tilde{\mid} \sigma \theta \alpha \imath)$ e incluso de las «manos» ( $\left.\chi \varepsilon \tilde{\rho} \rho \varsigma_{\varsigma}\right)$ entre los filósofos que han podido recibir alguna influencia del filósofo de Clazomene: cf. ibíd., pp. 278.308-310.

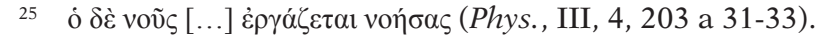

26 Luego no se puede negar toda inteligencia ni toda capacidad de ordenación al noûs. Por ende, existe cierta teleología en el pensamiento de Anaxágoras, pero limitada al nivel meramente «técnico» $\mathrm{y}$ «utilitario» sin alcanzar el nivel «sapiencial» $\mathrm{y}$ «honesto» que habrían exigido Platón y Aristóteles. A pesar de ello, autores como Silvestre y Sisko han negado la acción inteligente y planificadora del noûs: cf. SiLVESTRE, M. L., "Significato e ruolo del Nous nella filosofia di Anassagora», Il Contributo 12 (1988), pp. 29-52; Sisko, J. E., «Anaxagoras Betwixt Parmenides and Plato», Philosophy Compass 5 (2010), pp. 438-439.

27 Cf. Metaph., A, 1, 981 a $24-981$ b 6; 982 a 1; Eth. Nic., I, 1, 1094 a 14. 
el cuerpo humano ${ }^{28}$. Al contrario, debería haberse propuesto primeramente los fines perseguidos: en este caso, la vida humana y, con ella, todas las funciones que habrían de cumplirse para realizar el bien de ésta; después, en vista de tales objetivos, tendría que haber orientado su obrar procurando alcanzarlos ${ }^{29}$. Es por esto que, en el mismo diálogo al que nos referimos antes, Sócrates dirige una acusación análoga contra Anaxágoras, justo a continuación del texto arriba citado:

Me pareció que había sucedido algo muy parecido a como si uno afirmara que Sócrates hace todo lo que hace con inteligencia, y, luego, al intentar exponer las causas de lo que hago, dijera que ahora estoy aquí sentado por esto, porque mi cuerpo está formado por huesos y tendones, y que mis huesos son sólidos y tienen articulaciones que los separan unos de otros, y los tendones son capaces de contraerse y distenderse, y envuelven los huesos junto con las carnes y la piel que los rodea. Así que al balancearse los huesos en sus propias coyunturas, los nervios al relajarse y tensarse a su modo hacen que yo sea ahora capaz de flexionar mis piernas, y ésa es la razón por la que estoy yo aquí sentado con las piernas dobladas. Y a la vez, respecto de que yo dialogue con vosotros diría otras causas por el estilo, aduciendo sonidos, soplos, voces y otras mil cosas semejantes, descuidando nombrar las causas de verdad: que, una vez que a los atenienses les pareció mejor condenarme a muerte, por eso también a mí me ha parecido mejor estar aquí sentado, y más justo aguardar y soportar la pena que me imponen. ${ }^{30}$

La dureza de la crítica de Sócrates, Platón y Aristóteles no debe ocultarnos algo importante: Anaxágoras se vale del nô̂s lo bastante para concertar ordenadamente los entes. Sin embargo, se le escapa la parte primordial de la

28 Difícilmente podría pensar de otra forma quien reduce todo cambio a reorganización de ingredientes (DK 59 B 17; LM 25 D 15) y por tanto no conoce otro nivel que el de los «elementos», ignorando por entero la «forma» aristotélica. El concepto de finalidad como tal está, tanto en Platón como en Aristóteles, íntimamente ligado a la formalidad y éste

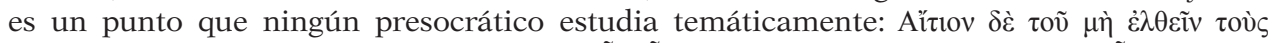

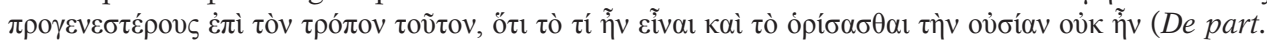
an., I, 1, 642 a 24-26).

29 Aristóteles considera incluso más avisado al obrero manual que a los filósofos naturalistas en general, porque aquel es capaz no sólo de prever las consecuencias de sus acciones sino incluso se las propone como objetivo: cf. De part. an., I, 1, 641 a 7-14.

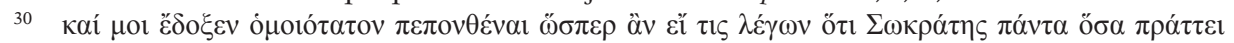

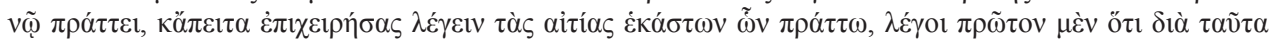

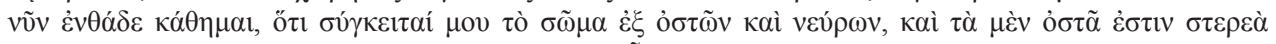

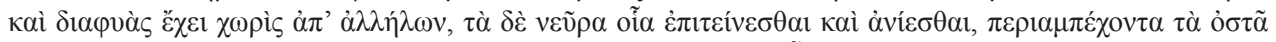

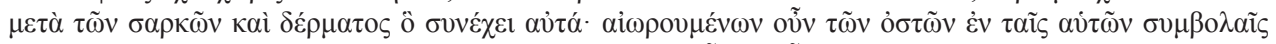

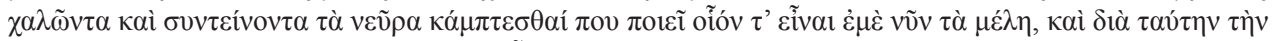

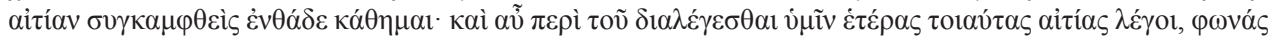

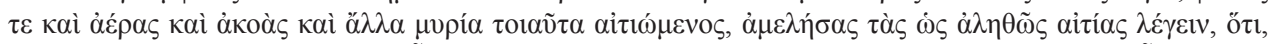

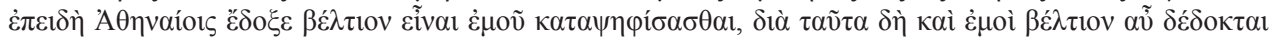

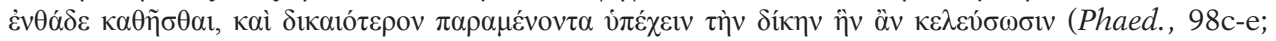
trad. García Gual, C.). 
teleología, porque sólo es capaz de atisbar (de modo implícito) fines próximos. Además, no toma en consideración la teleología y los fines en cuanto tales; es por ello que «bien» $\mathrm{o}$ «fin» son nociones que probablemente no hayan aparecido nunca en su tratado.

El único fragmento de Anaxágoras en que se podría hablar de cierta expresa referencia a alguna finalidad análoga a la que esperaban Sócrates y sus seguidores son unas líneas en que se refiere al resultado de las mezclas originadas por los movimientos provocados por el noûs:

También los hombres están compuestos y los demás vivientes que poseen alma. Existen asimismo ciudades construidas por los hombres y campos cultivados, como entre nosotros, y hay para ellos sol, luna y lo demás, como entre nosotros, y engendra la tierra para ellos muchas cosas y de toda clase, de lo cual ellos recolectan lo más beneficioso para el propio provecho. ${ }^{31}$

Sedley ha visto una analogía entre el noûs cósmico y el noûs presente en los seres humanos a los cuales se refiere este texto ${ }^{32}$. Puesto que los hombres, como todos los vivientes, disfrutan del nô̂s en cierta dosis (DK 59 B 12; LM 25 D 27), éste se conducirá en ellos de manera similar a como lo hace en el universo tomado como conjunto. El noûs se comporta —según Sedley-como un campesino, el cual es capaz de extraer el mayor beneficio de unos productos cuya innata capacidad de crecer y desarrollarse no ha inventado él. Ciertamente, Anaxágoras llega a adjudicar racionalidad al obrar del nô̂s cósmico y de sus manifestaciones humanas, pero no parece llegar más allá del concepto de «utilidad» faltándole el reconocimiento de la bondad misma ínsita en las cosas como tales ${ }^{33}$. Ni las cosas ni determinados eventos o actividades serían buenos por sí mismos sino tan sólo en función del «provecho» que se podría adquirir merced a ellos. Aunque este pensamiento utilitario supone racionalidad y una orientación teleológica hacia fines, éstos no son considerados como estrictamente «buenos», es decir, deseables por sí mismos. Por este motivo, sin negar que la fabricación del ser humano forme parte del designio racional y teleológico del noûs, no podemos acompañar a Sedley en decir que el universo está ordenado hacia el hombre como si éste fuese su perfección ${ }^{34}$.

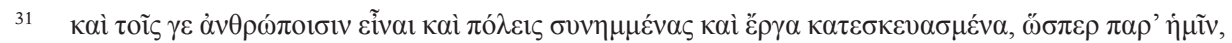

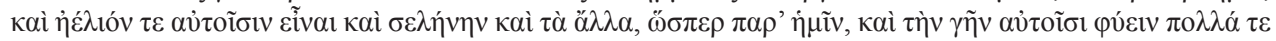

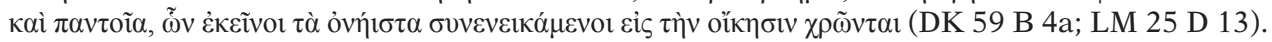

32 Cf. Sedley, D. N., Creationism and Its Critics in Antiquity, University of California Press, Berkeley, 2009, pp. 23-24.

33 Es lo que quise decir cuando afirmé que «el Clazomenio ha fundado el universo en el bien útil pero no en el bien honesto [Aristóteles, Ética a Nicómaco A 6: 1096b 13-14]» (Torrijos Castrillejo, D., «Anaxágoras de Clazomene», en: Fernández Labastida, F., Mercado, J. A. [eds.], Philosophica: Enciclopedia filosófica on line, URL: https://www.philosophica.info/ voces/anaxagoras/Anaxagoras.html, consultado 6 de abril de 2021).

34 Cf. SEDLEy, ibíd. 


\section{RECEPCIÓN DE LA TEORÍA DEL NOÛS}

Hemos partido de la crítica a Anaxágoras formulada por el Estagirita, la cual estaba orientada en una línea similar a la seguida por Platón. De acuerdo con ella, el carácter teleológico en la actuación del noûs quedaría en tela de juicio. Tal postura no impedía a Aristóteles afirmar reiteradamente que dicho principio constituía el bien y la causa de los bienes en su sistema. He aquí el problema que suscitó nuestra investigación. Existen dos soluciones a esta cuestión. La primera la hemos dado ya al referirnos a la cortedad de la teleología admitida por el pensador presocrático, insuficiente a los ojos de Platón y de su eminente discípulo. La segunda supone tener en cuenta la recepción de Anaxágoras en el pensamiento posterior. Aristóteles no analiza su filosofía por sí sola, sino en diálogo con Platón y la Academia. El concepto de bondad adquiere una importancia crucial en la lectura del pensamiento de Anaxágoras al ser empleado éste en confrontación con la filosofía de Espeusipo. Aunque el pensador jonio no haya hablado nunca del bien, Aristóteles cree ver subyacer ese concepto en su doctrina. Con probabilidad, esto le resulta fácil porque, al hablar del Clazomenio, no sólo tiene en cuenta su escrito sino también las interpretaciones sucesivas que fueron haciendo sus seguidores y cuantos iban mencionando su pensamiento de un modo u otro.

Veamos una prueba de esta progresiva y latente reinterpretación. En el pasaje de la Metafísica con el cual comenzamos, donde se alababa a Anaxágoras como juicioso entre los necios, se le atribuía en solitario la introducción del noûs; sólo a continuación se hablaba de la inserción de la bondad y la belleza en dicha teoría, relacionándola más bien con un grupo de personas (en plural) conceptuadas como "seguidores» suyos: "Vemos manifiestamente que Anaxágoras tocó estos temas [...]. Los que adoptaron este punto de vista, afirmaron que la causa de la belleza era el principio de los seres y, a la vez, el origen de donde surge el movimiento para las cosas existentes» ${ }^{35}$. A alguno podría antojársele exagerado referirse en este texto a ciertos «discípulos de Anaxágoras» tan sólo por la aparición del plural en el sujeto de la oración ${ }^{36}$. Sin embargo, existen razones de mayor peso para entenderlo así.

En primer lugar, Aristóteles ha hablado expresamente de las doctrinas de Anaxágoras aludiendo a sus discípulos, es decir, los que han integrado de un

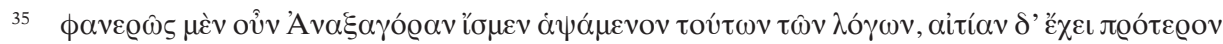

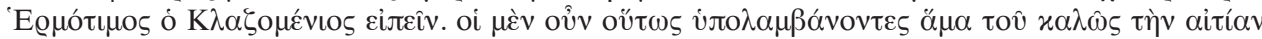

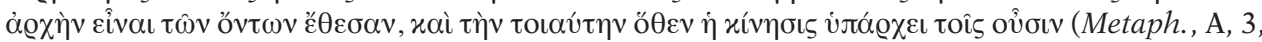
984 b 18-22; DK 59 A 58; LM 25 R 9).

36 Como se puede ver por el contexto, nuestra apelación a un grupo más o menos definido de «seguidores» podría verse fácilmente confutada diciendo que es Aristóteles quien engloba a distintas personas, incorporando incluso a algún mitógrafo anterior al presocrático (al punto reunirá, con Anaxágoras y Hermótimo, a Hesíodo y Parménides). 
modo u otro su pensamiento ${ }^{37}$. En segundo lugar, si prestamos atención a cómo fue interpretada la doctrina del Clazomenio por pensadores posteriores, podemos recordar a Diógenes de Apolonia que expresamente atribuye a su principio, el aire, cierta nóesis y lo hace disponer el mundo con la máxima

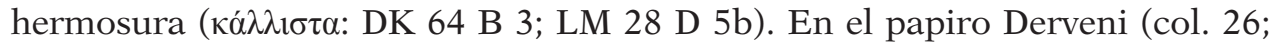
LM 30) se atribuye al noûs bondad ( $\dot{\alpha} \gamma \alpha \theta \tilde{\eta} \varsigma)$ debido a que produce el bien en el cosmos. Sobre todo merece nuestra atención el inmediato discípulo de Anaxágoras, Arquelao, quien igualmente habla del noûs (DK 60 A 18) y se ocupa ya por vez primera de «las cosas bellas y justas» ${ }^{38}$. Pues bien, por lo que toca a Arquelao, sabemos de su relación discente respecto de Anaxágoras y docente respecto de Sócrates. Sin duda este filósofo, el primer ateniense en ser considerado tal, ha debido de influir en la recepción socrática del Clazomenio. Por otro lado, el pasaje del Fedón no debe de expresar inquietudes lejanas al Sócrates histórico y, de hecho, encontramos asimismo en otros diálogos de Platón y en Jenofonte su vivo interés por la bondadosa providencia de los dioses cuya inteligencia (voṽs) ordena el mundo del mejor modo posible. El camino que parte de Anaxágoras y alcanza hasta Aristóteles pasa sin duda a través de Arquelao y Sócrates para llegar a Platón y a la Academia, donde el noûs se convertirá en uno de los conceptos clave para comprender la teoría de los primeros principios ${ }^{39}$.

Por estos motivos, en sus noticias sobre el Clazomenio, Aristóteles incluye tácitamente estas aportaciones posteriores, sobre todo porque pretende entrar en confrontación con la problemática planteada en la Academia. Como antes hemos sugerido, Espeusipo será el principal punto de referencia a la hora de comprender el noûs de Anaxágoras: el Clazomenio habría superado a Espeusipo porque su noûs —es decir, el primer principio- sería no sólo moviente sino asimismo el bien. Para Espeusipo, el noûs coincidiría con la divinidad suprema pero sería distinto del bien ${ }^{40}$. En cambio, para Aristóteles,

37 Se refiere en varias ocasiones a ciertos «discípulos» de Anaxágoras, oi $\pi \varepsilon \rho i ̀ ~ A v \alpha \xi \alpha \gamma o ́ p \alpha v:$ cf. De gen. et corr., I, 1, 314 a 25; 8, 345 a 25-31; De part. an., IV, 1, 677 a 5; Protrepticus, ed. Ross, fr. 5. Descubrir el efecto de Anaxágoras en los pensadores posteriores a él, a fin de comprender mejor los testimonios de Aristóteles, ha sido el propósito de la segunda parte de Torrijos-Castrillejo, D., Anaxágoras y su recepción en Aristóteles, pp. 265-370. En especial, quisiera resaltar la presencia en Aristóteles (Phys., I, 4, 187 a 29-30) de una interesante referencia a dos interpretaciones distintas de Anaxágoras difundidas entre «sus partidarios»: cf. ibíd., pp. 338-340. Véase también Torrijos-CAstrillejo, D., «An alternative model for understanding Anaxagoras' mixture», Philosophisches Jahrbuch 126 (2019), p. 9, nota 6.

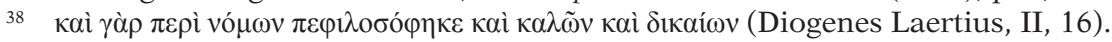

39 En la misma línea "etimológica» seguida por el papiro Derveni, hemos de llamar la atención especialmente sobre el Cratilo, donde Platón refiere la hipótesis de considerar

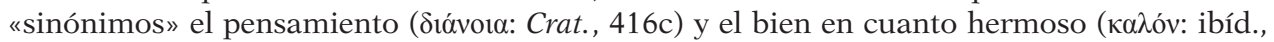

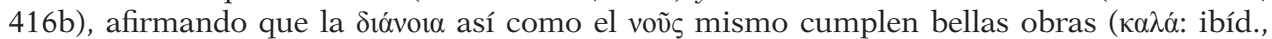

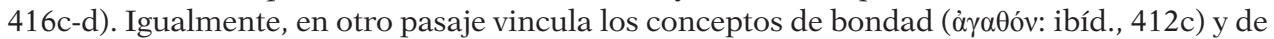

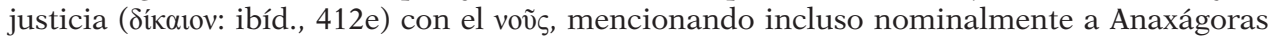
(ibíd., 413c).

40 Cf. Torrijos-Castrillejo, D., Anaxágoras y su recepción en Aristóteles, pp. 323-325. 
la bondad no sería de modo primario - como creía Espeusipo- un efecto del devenir, sino una actualidad originaria, dada prístinamente en la propia divinidad que es, asimismo, de carácter noético. Así lo defiende en el capítulo décimo de Metafísica Lambda (1075 a 14-15).

\section{CONCLUSIONES}

Hemos intentado solucionar el problema de la crítica aristotélica al uso del noûs por parte de Anaxágoras y su denominación como Bien o causa del bien. Se trataba de comprender la angosta senda que discurre entre una negación mecanicista de toda finalidad y una teleología articulada en torno al concepto del bien (encuadrada, en el fondo, en una filosofía de la sustancia y de la forma). Hemos mostrado que Anaxágoras desarrolla una teleología básica, cuya única apreciación es la capacidad organizativa de la inteligencia, que está en condiciones de disponer unas acciones en vista de otras. Sin embargo, ni el Clazomenio ha expuesto esto sino implícitamente, ni mucho menos ha convertido el bien en el objetivo del obrar deliberado. Por ello, creemos que se puede exponer esta capacidad rudimentaria de organización como un tipo de razonamiento teleológico fundado tan sólo en la «utilidad».

En resumidas cuentas, para esclarecer la aporética mención de la bondad respecto del noûs de Anaxágoras pronunciada por Aristóteles, hemos de hacernos cargo, primero, de los distintos enfoques con los que el Estagirita se aproxima hacia una doctrina heredada, según pueda obtener algo de ella para su propio discurso. En segundo término, es importante tener presente la recepción del pensamiento de nuestro presocrático entre diversos sujetos, en los años que median entre su enseñanza y los escritos de Aristóteles. Particularmente, vemos que la espontánea inclusión de la noción de bondad se debe a la aparición de este término en varios autores, pero recobra importancia principalmente en polémica con Espeusipo. En tercer lugar, está el planteamiento teleológico mismo de Anaxágoras, insuficiente a los ojos de Platón y Aristóteles. Con todo, a pesar de la crítica de éstos, sigue siendo posible atribuir al Clazomenio una teleología elemental, tácitamente integrada por él, pero distinta de aquel otro nivel superior de razonamiento teleológico propio de la filosofía de aquellos dos.

Universidad Eclesiástica San Dámaso, Madrid

David TorriJos-CAstrillejo

Facultad de Filosofía

dtorrijos@sandamaso.es

[Artículo aprobado en diciembre de 2015] $]^{41}$

41 Revisado con posterioridad para la publicación. 